\title{
EVALUASI KETEPATAN DIAGNOSIS DAN TINDAKAN DI RUMAH SAKIT PANTI RAPIH YOGYAKARTA PADA PENERAPAN JAMINAN KESEHATAN NASIONAL (JKN)
}

\author{
Nuryati \\ Rekam Medis Sekolah Vokasi Universitas Gadjah Mada \\ nur3yati@yahoo.com
}

\begin{abstract}
The purpose of this study is to investigate the implementation and to evaluate the accuracy of coding diagnosis and action also the factors that cause inappropriate coding in Hospital Panti Rapih Yogyakarta on the implementation of National Health Insurance.The type of this research is descriptive qualitative. The population subjects in this study are doctors, nurses, medical record employee, and independent verifier and as the population subject is inpatient medical record file of obstetrics and gynecology in 2012 as many as 339 files and all data from the existing measures in the Diary Sheet of Surgery Room Service Activity (Report of operation) in 2012 as many as 4925 action data. The data collection technique of this study are interviews, documentation study and observation, that related to the implementation of the encoding. The results of the research shows that the implementation of diagnosis coding and the action in Panti Rapih hospital Yogyakarta has been performed computerize by using Hospital Information System (SIRS) Inpatient that is performed by coding employee in the data processing. The process of coding a diagnosis by looking at the diagnosis of patients from the summary in and out of patients' sheet and see the results of the action in the Data Room Service Daily Activity Surgery (Report of Operations). The accuracy of the diagnosis code on the summary in and out inpatients' obstetrics and gynecology sheet is $44.56 \%$ which is in conformity with the ICD-10 and the action code on Inpatient SIRS is $57.12 \%$. Factors that affecting inaccuracies code diagnosis and the action are the understanding of the coding employee, it has never been done renewal program or update the database and ICD-10 in the Inpatient SIRS, coding audits have not been done.
\end{abstract}

Keywords: Encoding, accuracy, Diagnosis, Action, National Health Insurance.

\begin{abstract}
Abstrak
Tujuan penelitian ini adalah untuk mengetahui pelaksanaan dan evaluasi ketepatan pengkodean diagnosis dan tindakan serta faktor yang menyebabkan ketidakuratan pengkodean di Rumah Sakit Panti Rapih Yogyakarta pada penerapan Jaminan Kesehatan Nasional.Jenis penelitian ini adalah deskriptif kualitatif. Populasi subyek dalam penelitian ini adalah dokter, perawat, petugas rekam medis, dan verifikator independen dan sebagai pupulasi subyek adalah berkas rekam medis rawat inap obstetri dan ginekologi tahun 2012 sebanyak 339 berkas dan semua data hasil tindakan yang ada dalam lembar Data Harian Kegiatan Pelayanan Kamar Bedah (Laporan Operasi) tahun 2012 sebanyak 4925 data tindakan. Teknik pengumpulan data dengan wawancara, studi dokumentasi dan observasi terkait pelaksanaan pengkodean.Hasil penelitian menunujukkan bahwa pelaksanaan pengkodean diagnosis dan tindakan di RS Panti Rapih Yogyakarta sudah dilakukan secara komputerisasi dengan menggunakan Sistem Informasi Rumah Sakit (SIRS) Rawat Inap yang dilakukan oleh petugas coding di bagian pengolahan data. Proses pengkodean diagnosis dengan melihat diagnosis pada lembar ringkasan masuk keluar pasien dan melihat hasil tindakan di Data Harian Kegiatan Pelayanan Kamar Bedah (Laporan Operasi). Tingkat keakuratan kode diagnosis pada lembar ringkasan masuk keluar pasien rawat inap obstetri dan ginekologi sebesar 44,56\% kode yang sudah sesuai dengan ICD-10 dan kode tindakan pada SIRS Rawat Inap sebesar $57.12 \%$. Faktor-faktor yang mempengaruhi ketidakakuratan kode diagnosis dan tindakan yaitu
\end{abstract}


Nuryati. Evaluasi ketepatan diagnosis dan tindakan ...

pemahaman petugas coding, belum pernah dilakukannya pembaharuan program atau update database dan ICD-10 pada SIRS Rawat Inap, belum pernah dilakukan audit koding.

Kata Kunci: Pengkodean, Keakuratan, Diagnosis, Tindakan, Jaminan Kesehatan Nasional.

\section{PENDAHULUAN}

Berdasarkan Peraturan Presiden Republik Indonesia Nomor 12 Tahun 2013 tentang jaminan kesehatan, yang dimaksud dengan jaminan kesehatan adalah jaminan berupa perlindungan kesehatan agar peserta memperoleh manfaat pemeliharaan kesehatan dan perlindungan dalam memenuhi kebutuhan dasar kesehatan yang diberikan kepada setiap orang yang telah membayar iuran atau iurannya dibayar oleh pemerintah. Untuk menyelenggarakan program Jaminan Kesehatan, maka dibentuk sebuah badan hukum yang disebut Badan Penyelenggara Jaminan Sosial Kesehatan yang selanjutnya disingkat BPJS Kesehatan. Sedangkan pihak yang menyelenggrakan upaya pelayanan kesehatan disebut dengan Fasilitas Kesehatan. Fasilitas Kesehatan adalah fasilitas pelayanan kesehatan yang digunakan untuk menyelenggarakan upaya pelayanan kesehatan perorangan, baik promotif, preventif, kuratif maupun rehabilitatif yang dilakukan oleh Pemerintah, Pemerintah Daerah, dan/atau Masyarakat. Fasilitas Kesetahan terdiri atas fasilitas Kesehatan tingkat pertama dan Fasilitas Kesehatan rujukan tingkat lanjutan.

Rumah Sakit Panti Rapih Yogyakarta sebagai Fasilitas Kesehatan rujukan tingkat lanjutan bekerjasama dengan BPJS Kesehatan sebagai Badan Penyelenggara Jaminan Sosial Kesehatan dalam menerapkan pelayanan kesehatan pada Jaminan Kesehatan Nasional. Berdasarkan Peraturan Menteri Kesehatan Republik Indonesia Nomor 71 Tahun 2013 tentang pelayanan kesehatan pada Jaminan Kesehatan Nasional, bahwa salah satu bentuk pelayanan yang diberikan adalah administrasi pelayan. Administrasi pelayanan terdiri atas biaya pendaftaran pasien dan biaya administrasi lain yang terjadi selama proses perawatan atau pelayanan kesehatan pasien.

Menurut American Health Information Management Association dalam Hatta (2008), petugas pengkodean mampu menetapkan kode penyakit dan tindakan dengan tepat sesuai klasifikasi yang diberlakukan di Indonesia (ICD 10 dan ICD-9-CM) tentang penyakit dan tindakan medis dalam pelayanan dan manajemen kesehatan. Standar klasifikasi yang digunakan dalam penentuan kode tindakan adalah The International Classification of Diseases 9th Revision, Clinical Modification (ICD-9-CM) Volume 3. Menurut HCIA (1992), ICD-9-CM Volume 3 terdiri dari sejumlah kode numerik tanpa penggunaan karakter alphabet. Klasifikasi prosedur diterbitkan dalam volume sendiri sebagai volume 3 ICD-9-CM klasifikasi prosedur/tindakan dan berisi Daftar Tabular dan Indek Alfabet.

Menurut Hatta (2008), mangacu pada etik pengkodean dan keinginan untuk mencapai kualitas tinggi, data yang terkode sangat membantu penerbitan rincian tagihan biaya rawat yang tepat dan mengurangi resiko manajemen fasilitas asuhan kesehatan terkait. Dalam perancangan program compliance in coding (kepatuhan dalam pengkodean), salah satunya diadakan kegiatan auditing dan monitoring internal. Setiap organisasi pelayanan kesehatan harus mempunyai kebijakan dan prosedur untuk membuat pedoman, mengatur proses pengkodean dan menjamin konsistensi dari hasil pengkodean. Setiap organisasi kesehatan harus menetapkan program audit/monitoring untuk mereview keakuratan pengkodean berdasarkan aturan yang ada.

Coding, Costing, Clinical Pathway, dan Tecnology Information menjadi unsur-unsur pokok dalam pelayanan kesehatan pada Jaminan Kesehatan Nasional. Coding merupakan kegiatan menetapkan kode penyakit dan tindakan dengan tepat sesuai klasifikasi yang diberlakukan di Indonesia (ICD10) tentang penyakit dan tindakan medis dalam pelayanan dan manajemen kesehatan. Berdasarkan Keputusan Menteri Kesehatan Republik Indonesia Nomor 377/Menkes/SK/III/2007 tentang Standar Profesi Perekam Medis dan Informasi Kesehatan, disebutkan bahwa klasifikasi dan kodefikasi penyakit, masalah-masalah yang berkaitan dengan kesehatan dan tindakan medis merupakan kompetensi pertama Profesi Perekam Medis dan Informasi Kesehatan. Hal tersebut menunjukkan bahwa Profesi Perekam Medis dan Informasi Kesehatan memiliki kompetesi untuk melakukan kegiatan pengkodean. Tidak terdapat profesi lain dari seluruh jenis tenaga kesehatan yang 
memiliki kompetensi untuk melakukan kegiatan pengkodean, selain Profesi Perekam Medis dan Informasi Kesehatan. Hal ini menguatkan peran dan fungsi Profesi Perekam Medis dan Informasi Kesehatan dalam pelayanan kesehatan pada Jaminan Kesehatan Nasional.

Rumah Sakit Panti Rapih Yogyakarta memiliki lima tenaga Perekam Medis dan Informasi Kesehatan yang bertanggung jawab untuk melaksanakan kegiatan pengkodean dalam pelayanan kesehatan pada Jaminan Kesehatan Nasional. Terdapat satu orang verifikator independen dari pihak BPJS Kesehatan yang melakukan verifikasi terhadap kode yang ditentukan oleh tenaga Perekam Medis dan Informasi Kesehatan yang melaksanakan kegiatan coding tersebut. Oleh karena itu, perlu dilakukan penelitian lebih lanjut untuk mengetahui pelaksanaan pengkodean diagnosis di Rumah Sakit Panti Rapih Yogyakarta pada penerapan Jaminan Kesehatan Nasional.

Penelitian ini bertujuan untuk mengetahui pelaksanaan dan evaluasi ketepatan pengkodean diagnosis dan tindakan di Rumah Sakit Panti Rapih Yogyakarta pada penerapan Jaminan Kesehatan Nasional.

Jenis penelitian yang digunakan adalah deskriptif kualitatif dengan rancangan cross sectional. Objek yang digunakan oleh peneliti adalah berkas rekam medis rawat inap obstetri dan ginekologi tahun 2012 sebanyak 339 berkas dan semua data hasil tindakan yang ada dalam lembar Data Harian Kegiatan Pelayanan Kamar Bedah (Laporan Operasi) tahun 2012 sebanyak 4925 data tindakan. Teknik pengumpulan data dengan wawancara kepada dokter, perawat, petugas rekam medis, dan verifikator independen. Teknik pengumpulan data yang lain adalah studi dokumentasi pada berkas rekam medis dan observasi terkait pelaksanaan pengkodean.

\section{PEMBAHASAN}

\section{Pelaksanaan Pengkodean Diagnosis dan Tindakan di Rumah Sakit Panti Rapih}

Pelaksanaan pengkodean di Rumah Sakit Panti Rapih Yogyakarta ditinjau berdasarkan lima unsur manajemen, meliputi man, money, material, machine, dan method.
1. Man

a. Pihak-pihak yang terlibat dalam kegiatan pengkodean di Rumah Sakit Panti Rapih Yogyakarta meliputi pasien, dokter, petugas rekam medis dan informasi kesehatan bagian pengkodean, verifikator internal dan verifikator independen.

b. Pasien yang dimaksud adalah semua pasien BPJS Kesehatan yang mendapatkan pelayanan kesehatan atas kondisi yang dideritanya di Rumah Sakit Panti Rapih Yogyakarta. Pasien BPJS Kesehatan yang dilayani di Rumah Sakit Panti Rapih Yogyakarta sebesar $20 \%$ dari total pasien.

c. Dokter yang dimaksud adalah semua dokter yang melakukan pelayanan terhadap pasien BPJS Kesehatan di Rumah Sakit Panti Rapih Yogyakarta.

d. Petugas rekam medis dan informasi kesehatan yang dimaksud adalah petugas yang melaksanakan kegiatan pengkodean diagnosis pasien BPJS Kesehatan di Rumah Sakit Panti Rapih Yogyakarta. Terdapat lima orang petugas pengkodean yang terlibat. Seluruh petugas pengkodean merupakan lulusan D3 Rekam Medis, lulus tes kredensial, dan pernah mengikuti pelatihan pengkodean serta ada yang sudah tersertifikasi.

e. Verifikator independen adalah pihak yang melakukan verifikasi terhadap kode diagnosis yang dihasilkan petugas pengkodean atas diagnosis yang ditegakkan oleh dokter yang melayani pasien. Verifikator independen berasal dari pihak BPJS Kesehatan. Terdapat seorang verifikator independen untuk Rumah Sakit Panti Rapih Yogyakarta, yaitu seorang dokter.

f. Verifikator internal adalah pihak yang melakukan verifikasi terhadap kode diagnosis yang ditentukan oleh petugas pengkodean sebelum dilaporkan kepada verifikator independen. Terdapat seorang verifikator internal berasal dari pihak Rumah Sakit Panti Rapih Yogyakarta, yaitu seorang dokter. 


\section{Money}

a. Instalasi Rekam Medis Rumah Sakit Panti Rapih Yogyakarta tidak mengalami kendala terkait dengan money. Pengaturan keuangan di Rumah Sakit Panti Rapih Yogyakarta dilakukan secara terpusat.

b. Pengaturan keuangan dari pusat telah mengatur penggajian petugas pengkodean secara menyeluruh. Besarnya gaji yang diterima petugas pengkodean telah disesuaikan dengan beban kerjanya. Artinya, tidak ada perlakuan khusus (penambahan upah) terkait penghasilan yang diterima oleh masing-masing petugas pengkodean meskipun mereka memiliki peran dan fungsi yang kuat dalam pelayanan kesehatan pada Jaminan Kesehatan Nasional.

\section{Material}

a. Diagnosis yang telah ditegakkan oleh dokter yang memberikan pelayanan terhadap pasien merupakan materi yang dikode oleh petugas pengkodean.

b. Dalam pelaksanaannya, petugas pengkodean mengkode sesuai dengan diagnosis yang ditegakkan oleh dokter yang memeriksa pasien. Tetapi dalam kondisi tertentu, petugas pengkodean tidak serta merta mengkode sesuai dengan diagnosis yang ditegakkan oleh dokter tersebut. Misal, saat diagnosis dirasa kurang lengkap, salah penentuan diagnosis utama dan diagnosis tambahan, dan saat terjadi over coding.

c. Untuk mengatasi masalah pengkodean saat diagnosis dirasa kurang lengkap, petugas pengkodean dapat mengusulkan kepada dokter tersebut dengan cara konsultasi terkait kondisi yang belum termasuk ke dalam diagnosis yang ditegakkan oleh dokter tersebut setelah melalui penelaahan pada berkas rekam medis pasien. Jika usulan diterima, maka dokter bertanggung jawab atas diagnosis yang ditambahkan tersebut dan petugas pengkodean menambahkan kode diagnosis yang ditambahkan tersebut. Masalah kurang lengkapnya diagnosis yang ditegakkan ini, biasanya disebabkan karena diagnosis yang disampaikan kepada petugas pengkodean belum merupakan hasil final. Sehingga setelah berkas sampai di Instalasi Rekam Medis dan dipelajari lebih lanjut, ternyata masih ditemukan beberapa hal yang belum termasuk ke dalam diagnosis yang telah ditegakkan sebelumnya.

d. Untuk mengatasi masalah salah penentuan diagnosis utama dan diagnosis tambahan, petugas pengkodean menerapkan aturan re-seleksi yang terdapat di dalam ICD-10. Namun demikian, petugas pengkodean tidak serta merta menerapkan aturan reseleksi tersebut. Diskusi dengan dokter yang melakukan pemeriksaan terhadap pasien tersebut tetap dilakukan terlebih dahulu. Jika usulan diterima, maka dokter bertanggung jawab atas diagnosis yang ditambahkan tersebut dan petugas pengkodean menambahkan kode diagnosis yang ditambahkan tersebut. Masalah salah penentuan diagnosis utama dan diagnosis tambahan biasanya disebabkan kurang telitinya dokter dalam meletakkan (menuliskan) diagnosis pada kolom isian diagnosis utama dan diagnosis tambahan. Dokter juga tidak memiliki cukup waktu untuk menuliskan pada kolom isian yang sesuai, sehingga semua diagnosis diletakkan (dituliskan) di satu kolom isian.

e. Untuk mengatasi masalah saat terjadi over coding, petugas pengkodean memberikan peringatan kepada dokter. Sejak awal setiap pasien yang datang berkunjung ke Rumah Sakit Panti Rapih, telah diperkirakan besaran sumber daya yang akan dihabiskan untuk melayani masing-masing pasien tersebut. Perkirakan besaran sumber daya yang akan dihabiskan tersebut yang menjadi batasan apakah telah terjadi over coding. Apabila telah melebihi batasan tersebut, maka telah terjadi over coding. Saat terjadi over coding, maka petugas pengkodean memberikan peringatan kepada dokter 
tersebut agar melakukan peningkatan efektifitas dan efisiensi pelayanan. Permasalahan ini biasanya terjadi karena pada beberapa kondisi pasien, dokter hanya melihat gejala klinis pasien untuk menentukan diagnosis, tanpa perlu menggunakan pemeriksaan penunjang. Sehingga selama dokter masih melihat gejala klinis pasien belum membaik, maka pelayanan akan terus diberikan. Hal ini juga menjadi masalah tersendiri terkait penegakkan diagnosis untuk kepentingan BPJS Kesehatan. Dokter hanya menegakkan diagnosis berdasarkan gejala klinis, tanpa menggunakan pemeriksaan penunjang. Di sisi lain, verifikator independen membutuhkan informasi terkait pemeriksaan penunjang. Akibatnya sering terjadi penolakan dari verifikator independen atas suatu klaim.

\section{Machine}

a. Peralatan yang digunakan dalam proses pengkodean diagnosis di Rumah Sakit Panti Rapih Yogyakarta meliputi perangkat komputer yang dilengkapi dengan aplikasi grouper INA-CBGs, program pengkodean yang terdiri atas ICD-10 dan ICD-9-CM electronic, dan SIMRS

b. Terdapat dua unit komputer yang digunakan untuk pengkodean diagnosis di Rumah Sakit Panti Rapih Yogyakarta.

c. Aplikasi grouper yang digunakan untuk pengkodean diagnosis di Rumah Sakit Panti Rapih Yogyakarta adalah INA-CBG's 4.0.

d. Aplikasi grouper dan SIMRS belum terintegrasi, sehingga harus kerja dua kali.

\section{Method}

a. Kerjasama antara Rumah Sakit Panti Rapih Yogyakarta dengan BPJS Kesehatan mulai tanggal 1 Januari 2014.

b. Secara umum tidak terdapat perbedaan antara proses pengkodean sebelum dan sesudah kerjasama Rumah Sakit Panti Rapih Yogyakarta dengan BPJS Kesehatan. Perbedaannya terletak pada adanya proses efisiensi yang terjadi, baik efisiensi pemeriksaan maupun efisiensi obat.

c. Terdapat SPO terkait pengkodean diagnosis pasien BPJS Kesehatan. SPO belum mengatur terkait reward and punishment.

d. Belum terdapat (masih dalam proses penyusunan) panduan terkait pengkodean pasien BPJS Kesehatan.

\section{Evaluasi Ketepatan Kodefikasi Diagno- sis dan Tindakan}

Pengkodean dilaksanakan oleh empat petugas rekam medis yang berada di bagian olah data. Tiga diantara petugas pengkodean memiliki masing-masing tanggung jawab, yaitu sebagai penanggung jawab pengkodean IGD, rawat jalan, rawat inap, satu petugas olah data membantu pekerjaan semua petugas pengkodean. Petugas pengkodean di Rumah Sakit Panti Rapih hanya bertugas melaksanakan pengkodean sesuai dengan struktur organisasi yang telah ada, sehingga tidak terjadi rangkap tugas dalam pelaksanaan pekerjaan.

Petugas pengkodean pasien rawat inap di Rumah Sakit Panti Rapih Yogyakarta ada dua, satu berlatar belakang pendidikan D3 Rekam Medis dan sudah mengikuti pelatihan Training of trainer ICD-10. Petugas pengkodean yang berlatar pendidikan bukan D3 Rekam Medis juga pernah mengikuti pelatihan ataupun seminar namun seminar secara umum mengenai manajemen Rekam Medis.

Sumber daya manusia adalah petugas yang bertanggungjawab yang mampu berkarya secara optimal untuk mencapai tujuan organisasi. Perubahan paradigma profesi rekam medis menjadi profesi manajemen informasi kesehatan telah membawa perubahan terhadap pentingnya pembinaan sumber daya manusia khususnya tenaga profesi yang selama ini menekuni bidang pekerjaan tersebut.

Berdasarkan Keputusan Menteri Kesehatan Nomor 377/Menkes/SK/III/2007 tentang Standar Profesi Perekam Medis dan Informasi Kesehatan, perekam medis dan informasi kesehatan adalah seseorang yang telah menyelesaikan pendidikan formal Rekam Medis 
dan Informasi Kesehatan sehingga memiliki kompetensi yang diakui oleh pemerintah dan profesi serta mempunyai tugas, tanggungjawab, wewenang, dan hak secara penuh untuk melakukan kegiatan pelayanan rekam medis dan informasi kesehatan pada unit pelayanan kesehatan.

Berdasarkan Kepmenkes No. 377/Menkes/SK/ III/2007 yang menyatakan bahwa kualifikasi pendidikan rekam medis berlatar pendidikan Rekam Medis dan Informasi Kesehatan. Namun petugas pengkodean di Rumah Sakit Panti Rapih masih ada yang bukan lulusan Rekam Medis dan Informasi Kesehatan, walaupun petugas tersebut sudah pernah mengikuti pelatihanpelatihan untuk menunjang pekerjaanya. Hal ini sesuai dengan pernyataan Hatta (2008) sumber daya manusia khususnya tenaga profesi yang selama ini menekuni bidang pekerjaan tersebut harus mengikuti pelatihan, pembinaan, dan pengembangan terlebih dahulu.

Berdasarkan hasil observasi yang dilakukan peneliti di Instalasi Rekam Medis Rumah Sakit Panti Rapih Yogyakarta, fasilitas yang digunakan dalam menunjang pelaksanaan pengodean di Rumah Sakit Panti Rapih yaitu dengan menggunakan program SIRS menu pengodean, ICD-10 volume 1 dan 3, ICD-9 CM, Kamus kedokteran, daftar singkatan yang dibakukan, kamus singkatan Internasional, dan kamus Bahasa Inggris.

Menurut Abdelhak, dkk (2001), “computer software called encoder is available to assist in the coding prosess". (perangkat lunak komputer yang dinamakan encoder tersedia untuk membantu proses pengkodean). Berdasarkan studi dokumentasi terhadap SPO nomor RSPR/S5P2/SPO.24 Rumah Sakit Panti Rapih Yogyakarta (2009), tentang pengkodean dan indeksing, pelaksanaan pengkodean kode diagnosis dan tindakan pasien rawat inap sudah dilakukan secara komputerisasi. Di dalam SPO tersebut disebutkan apabila kode penyakit belum ada maka pencarian kode penyakit menggunakan ICD-10 secara manual dan segera memasukkan kode tersebut ke dalam komputer. Di Rumah Sakit Panti Rapih Yogyakarta pelaksanaan pengkodean menggunakan fasilitas yang berguna untuk menunjang proses pengkodean, hal ini sesuai dengan SPO nomor RSPRS/S5P2/SPO.24. tentang pengkodean dan indeksing, dan sesuai dengan teori Abdelhak, dkk (2001).

Proses pengkodean dilakukan dengan menggunakan program yang sudah terdapat di komputer. Apabila terdapat diagnosis yang disingkat, maka petugas akan mencari di daftar singkatan yang sudah dibakukan oleh pihak rumah sakit ataupun mencarinya di daftar singkatan Internasional.

Pelaksanaan pengkodean dilakukan setelah berkas rekam medis selesai di assembling. Apabila di temukan berkas rekam medis yang tidak lengkap dalam pengisian diagnosis maupun tindakan, ataupun ditemukan diagnosis maupun tindakan yang tidak terbaca jelas, petugas rekam medis akan mengembalikan berkas rekam medis dan bertanya kepada dokter yang bersangkutan mengenai diagnosis dan tindakan.

Menurut Abdelhak, dkk (2001), petugas rekam medis dalam melaksanakan pengkodean harus menggunakan ICD-10. Di Rumah Sakit Panti Rapih Yogyakarta pelaksanaan pengkodean dilaksanakan menggunakan SIRS menu pengkodean. Hal ini sesuai dengan teori Abdelhak, dkk (2001) yang menyatakan "computer software called encoder is available to assist in the coding prosess". (perangkat lunak komputer yang dinamakan encoder tersedia untuk membantu proses pengkodean).

Menurut Abdelhak, dkk (2001), pengkodean harus dilaksanakan secara berurutan agar tidak terjadi kesalahan dalam melakukannya. Sebelum melakukan proses pengkodean, petugas rekam medis harus memeriksa kelengkapan lembar rekam medis dan kelengkapan catatan dokter, terutama catatan tentang diagnosis yang tertulis pada lembar ringkasan masuk dan keluar dan sudah terdapat tanda tangan dokter.

Di Rumah Sakit Panti Rapih Yogyakarta pengkodean dilaksanakan setelah berkas rekam medis selesai di assembling yaitu dengan memeriksa kelengkapan lembar rekam medis dan kelengkapan catatan dokter terutama catatan tentang diagnosis yang tertulis di lembar ringkasan masuk dan keluar. Hal tersebut sesuai dengan teori Abdelhak, dkk (2001) sebelum 
melakukan proses pengkodean, petugas rekam medis harus memeriksa kelengkapan lembar rekam medis dan kelengkapan catatan dokter, terutama catatan tentang diagnosis yang ditulis di lembar ringkasan masuk keluar dan sudah ada tanda tangan dokter.

Setelah petugas rekam medis memeriksa kelengkapan lembar rekam medis dan kelengkapan catatan dokter. Apabila tidak memahami tulisan dokter, petugas rekam medis di Rumah Sakit Panti Rapih Yogyakarta bertanya kepada dokter yang berperan sebagai pemberi diagnosis. Hal ini sesuai dengan Abdelhak, dkk (2001) apabila petugas rekam medis menemui hambatan dalam pemberian kode atau menemukan diagnosis, dokter bertanggungjawab untuk membantu.

Di Instalasi Rekam Medis Rumah Sakit Panti Rapih Yogyakarta, kebijakan yang mengatur tentang prosedur pengkodean sudah ada dan tertuang didalam SPO nomor RSPR/S5P2/ SPO.24, akan tetapi prosedur pengkodean masih menjadi satu antara prosedur pengkodean rawat inap, rawat jalan, dan rawat darurat.

Dengan adanya prosedur tetap pekerjaan dapat dilaksanakan sesuai dengan aturan yang benar secara efisien (Sabarguna, 2008). Berdasarkan hasil penelitian menunjukkan bahwa prosedur tetap di Rumah Sakit Panti Rapih Yogyakarta yang mengatur tentang pengkodean dan indeksing sudah ada, hal ini sudah sesuai teori (Sabarguna, 2008), akan tetapi prosedur pengkodean masih menjadi satu antara prosedur pengkodean rawat inap, rawat jalan, dan rawat darurat. prosedur tetap masih menjadi satu dan dalam proses revisi untuk memperisapkan akreditasi.

Keakuratan Kode Diagnosis dan Tindakan pada Pasien Rawat Inap RS Panti Rapih

Untuk mengetahui prosentase keakuratan kode diagnosis dan tindakan, peneliti melakukan studi dokumentasi terhadap 339 Berkas rekam medis dan terhadap 469 diagnosis pada lembar ringkasan masuk keluar dan 4925 data tindakan pada lembar operasi.

Di bawah ini merupakan data hasil pengkodean diagnosis dan tindakan pasien rawat inap, untuk lebih jelasnya dapat dilihat pada tabel dibawah ini:
Tabel 1: Hasil Analisis Keakuratan Kode Diagnosis dan Tindakan

\begin{tabular}{llllll}
\hline \multirow{2}{*}{ No } & \multirow{2}{*}{ Kriteria } & \multicolumn{2}{c}{ Diagnosis } & \multicolumn{2}{c}{ Tindakan } \\
\cline { 3 - 6 } & & Jumlah & $\mathbf{\%}$ & Jumlah & \% \\
\hline $\mathbf{1}$ & A & 209 & 44,56 & 377 & 57,12 \\
\hline $\mathbf{2}$ & B & 16 & 3,41 & 62 & 9,39 \\
\hline $\mathbf{3}$ & C & 44 & 8,95 & 63 & 9,55 \\
\hline $\mathbf{4}$ & D & 88 & 18,76 & 68 & 10,30 \\
\hline $\mathbf{5}$ & E & 114 & 24,30 & 90 & 13,64 \\
\hline & Jumlah & 469 & 100,00 & 660 & 100,00 \\
\hline
\end{tabular}

Dari tabel 1 diatas dapat diketahui prosentase ketidakakuratan dalam menentukan kode diagnosis pada lembar ringkasan masuk keluar pasien rawat inap obstetri dan ginekologi. Dari 339 berkas didapat diagnosis sebanyak 469 pada lembar ringkasan masuk keluar yang dianalisis terdapat $44,56 \%$ kode penyakit pasien yang sesuai/spesifik dengan ICD10 , kode penyakit yang hanya terdiri dari 3 karakter sebanyak $43,41 \%$, kode penyakit yang salah pada karakter keempat sebanyak $8,95 \%$, kode penyakit yang tidak sesuai dengan ICD-10 sebanyak 18.76\%, dan kode penyakit yang tidak terkode sebanyak $24,30 \%$. Kriteria A (kode tindakan tepat/spesifik) sebanyak 377 kode tindakan atau sebesar 57.12\% dari jumlah keseluruhan, sedangkan untuk kriteria B (kode tepat sampai digit kedua) sebanyak 62 kode tindakan atau sebesar 9.39\%, kriteria C (kode tepat sampai digit ketiga) sebanyak 63 kode atau sebesar 9.55\%. Kriteria D (kode tindakan tidak tepat) sebanyak 68 kode atau sebesar $10.30 \%$ dan kriteria E (tidak ada kode tindakan) sebanyak 90 kode atau sebesar $13.64 \%$.

Kriteria "A", menurut WHO (2004) bahwa subkategori empat karakter digunakan paling tepat untuk identifikasi, misalnya variasi tempat yang berbeda pada kategori tiga karakter untuk penyakit tunggal atau penyakit yang berdiri sendiri pada kategori tiga karakter untuk kondisi yang berkelompok. Menurut WHO (2002), petugas rekam medis diharuskan menggunakan kode tiga digit atau empat digit dari ICD-10.

Keakuratan kode diagnosis dengan kriteria " $\mathrm{A}$ " pada lembar ringkasan masuk keluar pasien rawat inap obstetri dan ginekologi adalah sebesar 44,56\%. Keakuratan kode diagnosis dengan ICD-10 perlu ditingkatkan karena menurut Hatta (2008), penerapan pengodean sistem ICD-10 digunakan untuk:

a. Mengindeks pencatatan penyakit dan tindakan disarana pelayanan kesehatan 
b. Masukan bagi sistem pelaporan diagnosis medis

c. Memudahkan proses penyimpanan dan pengambilan data terkait diagnosis karasteristik pasien dan penyedia pelayanan

d. Bahan dasar dalam pengelompokan DRGs (diagnosis-related groups) untuk sistem penagihan pembayaran biaya pelayanan

e. Pelaporan nasional dan internasional morbiditas dan mortalitas

f. Tabulasi data pelayanan kesehatan bagi proses evaluasi perencanaan pelayanan medis.

g. Menentukan bentuk pelayanan yang harus direncanakan dan dikembangkan sesuai kebutuhan zaman

h. Analisis pembiayaan pelayanan kesehatan

i. Untuk penelitian epidemiologi dan klinis

Kriteria "B", kode yang termasuk ke dalam kategori ini digunakan dalam proses pelaporan yang hanya membutuhkan tiga karakter. Untuk morbiditas pasien rawat inap sendiri, pelaporan ke dinas kesehatan menggunakan kategori tiga karakter. Kategori tiga karakter merupakan karakter yang wajib dilaporkan ke WHO dari tiap Negara (WHO, 2002).

Di Rumah Sakit Panti Rapih Yogyakarta terdapat beberapa Kriteria "C" kode penyakit yang hanya dituliskan sampai karakter ketiga hal ini tidak berpengaruh terhadap pelaporan morbiditas karena kode diagnosis tiga karakter yang wajib dilorkan WHO. Namun, hal ini kan menjadi masalah bagi keperluan penelitian dan pendidikan mengenai penyakit, karena kedua hal tersebut membutuhkan kekhususan (spesifikasi).

Kriteria "E", kode yang termasuk dalam kategori ini adalah diagnosis rangkap, namun beberapa diagnosis rangkap dalam lembar ringkasan masuk keluar tidak dikode. Menurut Hatta (2008), untuk pelaporan secara kelompok bagi analisis penyebab tunggal morbiditas yang diambil adalah kode kondisi utama, sedangkan untuk pengindeksan kode semua kondisi ini harus dicatat, dikode untuk kemudian disimpan agar dapat memenuhi kebutuhan setempat yang lebih luas.

Menurut Abdelhak (2001), kesesuaian data dan informasi yang disajikan dengan informasi yang dibutuhkan sangat berperan dalam proses pengambilan keputusan. Untuk dapat menghasilkan data serta informasi yang baik serta dapat digunakan sebagai dasar dalam pengambilan keputusan manajemen, dibutuhkan peran aktif petugas dalam melakukan proses pengolahan data.
Dari perhitungan yang dilakukan peneliti terkait dengan keakuratan kode tindakan, masih ditemukan kode yang tidak tepat dan tidak terisi. Persentase keakuratan kode tindakan tertinggi terletak pada kriteria A (kode tindakan tepat/spesifik) sebanyak 377 kode tindakan atau sebesar $57.12 \%$ dari jumlah keseluruhan.

Berdasarkan hasil analisis ketepatan kode tindakan di RS Panti Rapih Yogyakarta masih terdapat tindakan yang tidak tepat untuk kriteria D (kode tidak tepat) sebanyak 68 atau $10.30 \%$ yang tidak tepat. Selain itu juga terdapat kode tindakan yang tidak dikode untuk krieria $\mathrm{E}$ (kode tindakan yang tidak terisi) sebanyak 90 atau $13.64 \%$. petugas rekam medis harus berupaya untuk meminimalisir ketidaktepatan kode tindakan yang merupakan tanggung jawab petugas rekam medis sebagai pemberi kode tindakan.

Berdasarkan Farzandipour (2009), keakuratan dibagi atas keakuratan pada digit utama dan digit keempat, perbandingan keakuratan antara petugas coding yang sudah berpengalaman dengan yang belum, perbandingan kode dengan menggunakan database dengan menggunakan buku ICD-9-CM dan pengecekan ulang kode yang di dalam daftar tabel dengan yang hanya menggunakan alfabet indeks. Perbedaan pada penelitian yang dilakukan sekarang di RS Panti Rapih Yogyakarta adalah peneliti membagi kriteria 5 kriteria dalam menentukan keakuratan kode tindakan, yaitu kriteria A (kode spesifik/ tepat, kriteria B (kode tepat pada digit kedua), kriteria $\mathrm{C}$ (kode tepat pada digit ketigas), kriteria D (kode tidak tepat), dan kriteria E (kode tidak terisi).

Tenaga rekam medis bertanggungjawab atas keakuratan kode dari suatu diagnosis yang sudah ditetapkan oleh tenaga medis (Budi, 2011). Di Rumah Sakit Panti Rapih Yogyakarta masih terdapat diagnosis yang belum akurat sesuai ICD-10, petugas rekam medis seharusnya berupaya meminimalisir ketidakakuratan karena keakuratan kode diagnosis merupakan tanggungjawab petugas rekam medis sebagai pemberi kode diagnosis.

\section{SIMPULAN}

1. Pelaksanaan pengkodean diagnosis dan tindakan di Instalasi Rekam Medis RS Panti Rapih Yogyakarta dilakukan oleh 2 orang petugas coding, salah satu bertindakan sebagai petugas coding rawat inap pasien Jamkesmas, dan salah 
satu bertindak sebagai petugas coding untuk pasien rawat inap. Latar belakang pendidikan D3 Rekam Medis dan diluar rekam medis. Proses pengkodean di RS Panti Rapih sudah terkomputerisasi.

2. Analisis keakuratan kode diagnosis dan tindakan belum tercapai secara maksimal, hasil analisis keakuratan kode diagnosis terdapat 44,56\% kode yang sudah sesuai dengan ICD-10 dan terdapat 377 atau $57.12 \%$ kode tindakan yang sudah sesuai dengan ICD-9-CM.

3. Faktor-faktor penyebab ketidakakuratan pengkodean kode dan diagnosis dan tindakan kasus bedah pasien rawat inap di RS Panti Rapih Yogyakarta adalah Sumber Daya Manusia (SDM), update database ICD-10 dan ICD-9$\mathrm{CM}$, dan belum dilakukannya evaluasi/audit tentang kode diagnosis dan tindakan.

\section{SARAN}

1. Sebaiknya Kepala Intalasi Rekam Medis mulai merencanakan melakukan kegiatan evaluasi/ audit terhadap kode diagnosis dan tindakan, agar meningkatkan keakuratan kode yang digunakan sebagai pelaporan

2. Sebaiknya dokter di RS Panti Rapih Yogyakarta meningkatkan kelengkapan data yang dituliskan dalam berkas rekam medis dengan cara sosialiasi.

3. Sebaiknya petugas pengkodean lebih spesifik dalam menentukan kode diagnosis dan tindakan. Sebaiknya petugas pengkodean menggunakan ICD-10 dan ICD-9 CM yang sudah di-update dan memperbaharui database yang digunakan sebagai alat pengkodean.

4. Sebaiknya petugas rekam medis memberikan sosialisasi kepada dokter baru mengenai peraturan tentang daftar nama singkatan penyakit dan peraturan lain yang ada di rekam medis.

\section{DAFTAR PUSTAKA}

American Academy of Professional Coders (AAPC). 2013. What Is ICD-9-CM? Diakses dari http:// www.aapc.com/resources/medical-coding/ icd9.aspx tanggal 31 mei 2013 pukul 8.46 AM.

Abdelhak, M. 2001. Health Information Management Of Strategic Resource. Sydney: W.B.Saunders Company.
Arcury, T.A., Sara, A. Q. 1998. Qualitative Methods in Arthritis Research: Sampling and Data Analysis. Methods Article. North Carolina: American College of Rheumatology. Diakses dari http://onlinelibrary.wiley.com tanggal 12 Juni 2013

Arifin, M. 2012. 5M Dalam Manajemen diakses dari http://indonesiapublichealth.blogspot.com

Arikunto, S. 2010. Prosedur Penelitian Suatu Pendekatan Praktik. Jakarta: Rineka Cipta.

Azwar, S. 2011. Metode Penelitian. Yogyakarta: Pustaka Belajar

Budi, S.C. 2011. Manajemen Unit Kerja Rekam Medis. Yogyakarta: Quantum Sinergis Media.

Bungin, B. 2009. Penelitian Kualitatif Komunikasi, Ekonomi, Kebijakan Publik, Dan Ilmu Sosial Lainnya. Jakarta : Kencana Prenada Media Group

Centers For Disease Control And Prevention (CDC). 2012. International Classification of Diseases, Ninth Revision, Clinical Modification (ICD-9-CM). Diakses dari http:// www.cdc.gov $/ \mathrm{nchs} / \mathrm{icd} / \mathrm{icd} 9 \mathrm{~cm} . h$ tm tanggal 31 Mei 2013 pukul 8.37 AM.

Cheng, P., Annette, G., Kerin, M. R., Lindsay, P. 2009. The risk and consequences of clinical miscoding due to inadequate medical documentation: a case study of the impact on health services funding. Health Information Journal. Australia. Diakses dari www.himaa. org.au tanggal 12 Juni 2013

Faciszewski. T., Jensen. R., Berg. RL., 2003. Procedural coding of spinal surgeries (CPT-4 versus ICD-9-CM) and decisions regarding standards: a multicenter study. Jurnal. Amerika Serikat: Department of Orthopaedic Spine Surgery. Diakses dari http://www.ncbi. nlm.nih.gov tanggal 24 Juni 2013

Farzandipour, M. 2009. Evaluation of Factors Influencing Accuracy of Principal Procedure Coding Based on ICD-9-CM. Online Research Journal Perspectives in Health Information Management. Iran: Kashan University of Medical Sciences. Diakses dari http://www. ncbi.nlm.nih.gov tanggal 12 Juni 2013

Hasibuan, M.S.P. 2009. Manajemen Sumber Daya Manusia. Jakarta: Bumi Aksara 
Hatta, G.R. 2008. Pedoman Managemen Informasi Kesehatan Di Sarana Pelayanan kesehatan. Jakarta: UI Press.

Health Care Innovation Award (HCIA). 1992. International Classification of Diseases 9th Revision Clinical Modification Volume 3. Maryland: HCIA.

Huffman, E. 1994. Health Information Management. Illinois: Physisian‘s Record Company.

International Federation of Health Records Organizations (IFRHO). 2006. Education Modules for Basic Health Record Practice. Amerika

Keputusan Menteri Kesehatan RI No. 377/MENKES/ SK/III/2007 tentang Standar Profesi Perekam Medis.

Moleong, M.A. 2007. Metode Penelitian Kualitatif. Bandung: Remaja Rosdakarya

Notoatmodjo, S. 2005. Metodelogi Penelitian Kesehatan. Jakarta: Rineka Cipta.

Peraturan Menteri Kesehatan RI Nomor. 269/ Menkes/Per/III/2008 tentang rekam medis. Diakses dari perpustakaan.depkes.go.id.

RS Panti Rapih Yogyakarta. 2009 Buku Pedoman Pelayanan Rekam Medis (BPPRM) Tahun 2009. Yogyakarta.

RS Panti Rapih Yogyakarta. 2009. Profil Rumah Sakit Panti Rapih Yogyakarta Tahun 2009. Yogyakarta.
RS Panti Rapih Yogyakarta. 2009. Standar Prosedur Operasional (SPO) Tahun 2009. Yogyakarta

Santos, S., Gregory, M., Kathryn, B., Kerin, M. R. 2008. Organisational factors affecting the quality of hospital clinical coding. Health Information Journal. Australia. Diakses dari www.server-web.com tanggal 12 Juni 2013

Skurka, B.S. 2005. Health Information Management. Chicago: AHA Press

Sugiyono. 2009. Metode Penelitian Kuantitatif, Kualitatif Dan $R \&$ D. Bandung: Alfabeta.

Undang-Undang Praktik Kedokteran Nomor 29 Tahun 2004 Pasal 46 diakses dari www. depkes.go.id pada tangga 7 Juni 2013

Undang-Undang Nomor 44 tahun 2009 Pasal 5 tentang Rumah Sakit diakses dari www.hukor. depkes.go.id pada tangga 7 Juni 2013

WHO. 2002. Medical Records Manual: A Guide for Developing Countries. Regional Office For The Western Pasific: World Health Organization.

2003. Improving Data Quality: A Guide for Developing Countries. Regional Office For The Western Pasific: World Health Organization.

Wijono, D. 1999. Manajemen Mutu Pelayanan Kesehatan, Teori Strategi dan Aplikasi Volume 2. Surabaya: Airlangga University Press. 